\title{
RANKL Enhances Macrophage Paracrine Pro-Calcific Activity in High Phosphate-Treated Smooth Muscle Cells: Dependence on IL-6 and TNF- $\alpha$
}

\author{
Kate Ann Deuella Andrea Callegaria Cecilia M. Giachelli ${ }^{a}$ b \\ Michael E. Rosenfeld ${ }^{b, c}$ Marta Scatena ${ }^{a}$ \\ Departments of ${ }^{a}$ Bioengineering, ${ }^{b}$ Pathology and ${ }^{c}$ Environmental and Occupational Health Sciences, \\ University of Washington, Seattle, Wash., USA
}

\section{Key Words \\ Cardiovascular disease - IL-6 - Macrophages - RANKL • \\ TNF- $\alpha \cdot$ Vascular calcification}

\begin{abstract}
Background: Vascular calcification is highly correlated with cardiovascular disease (CVD) morbidity and mortality, and it is associated with inflammation. Receptor activator of NF-кB ligand (RANKL) inhibition in vivo has been shown to reduce vascular calcification in a mouse model of atherosclerosis. Therefore, we tested the hypothesis that RANKL regulates smooth muscle cell (SMC) calcification by modulating macrophage production of pro-calcific cytokines. Methods: We used a bone marrow-derived macrophage (BMDM)/SMC Coculture system and examined the effects of RANKL on BMDM activation and SMC matrix calcification. Results: Treatment with RANKL alone did not stimulate SMC calcification induced by elevated phosphate. BMDMs differentiated with macrophage colony-stimulating factor and placed in co-culture with SMCs increased phosphate-induced SMC calcification. RANKL added to the BMDM/SMC co-cultures further enhanced SMC calcification. Treatment of BMDMs with RANKL resulted in increased expression of IL- 6 and TNF- $\alpha$. Thus, increased expression of these pro-calcific cytokines in
\end{abstract}

macrophages may mediate RANKL-induced SMC calcification in a paracrine fashion. Addition of neutralizing IL- 6 and TNF- $\alpha$ antibodies together with RANKL treatment significantly reduced the RANKL induction of SMC calcification. Conclusion: RANKL activation of pro-inflammatory and procalcific pathways in macrophages may contribute to vascular calcification and inflammation.

Copyright $\odot 2012$ S. Karger AG, Base

\section{Introduction}

Vascular calcification, a type of ectopic soft tissue mineralization, increases the risk of cardiovascular mortality. Arterial wall mineralization is estimated to be present in the vast majority of patients affected by cardiovascular disease (CVD) [1]. Patients with end stage renal disease generally have extensive medial and intimal calcification that is associated with a highly significant increase in cardiovascular mortality compared to the general population [2]. It is now estimated that $>15 \%$ of the

Kate Ann Deuell and Andrea Callegari contributed equally to this study.

\section{KARGER}

Fax +4161306 1234

E-Mail karger@karger.ch

www.karger.com (c) 2012 S. Karger AG, Basel

$1018-1172 / 12 / 0496-0510 \$ 38.00 / 0$

Accessible online at:

www.karger.com/jvr
Dr. Marta Scatena

Department of Bioengineering, University of Washington

Box 358056

Seattle, WA 98195 (USA)

Tel. +1 206543 5789, E-Mail mscatena@uw.edu 
population of the United States have chronic kidney disease (2010 US Renal Data System Annual Data Report http://www.usrds.org/). Type II diabetics are an additional population affected by elevated vascular calcification [3]. Given the dramatic rise in diabetes and metabolic syndrome in the US, increased frequencies of vascular calcification and CVD are to be expected in the coming decade.

In the aorta, calcification promotes congestive heart failure by compromising vessel compliance and elasticity. In coronary arteries, calcium deposits may cause atherosclerotic plaque instability [1]. In human lesions, the process leading to vascular calcification appears to follow an osteochondrogenic pathway analogous to endochondral bone formation; in mouse lesions, vascular calcification is often accompanied by the appearance of cartilaginous metaplasia that subsequently mineralizes $[4,5]$. Recent in vitro and in vivo studies on the mechanisms modulating vascular calcification indicate that it is a highly regulated process involving vascular smooth muscle (SM) cells (SMCs). Inorganic phosphate and bone morphogenetic proteins (BMPs) have emerged as key regulators of osteochondrogenic transdifferentiation of SMCs. Up-regulation of the osteochondrogenic transcription factor Runx2 and down-regulation of SMC lineage markers appear to be key processes in vascular cell-dependent mineralization $[6,7]$.

Inflammation frequently accompanies atherosclerotic plaque calcification. Macrophages and T lymphocytes infiltrating the atherosclerotic lesion produce pro-inflammatory cytokines and other regulators of calcification that may induce SMC apoptosis as well as osteochondrogenic differentiation. In vitro, these effects have been shown to be mediated at least in part by TNF- $\alpha$, oncostatin $\mathrm{M}$ and oxidative stress [8-11].

RANKL signals through its cell surface receptor RANK, a member of the TNF receptor superfamily. This interaction can be inhibited by the soluble decoy receptor for RANKL, osteoprotegerin (OPG). RANK is required for osteoclast differentiation and plays additional roles in modulating adaptive immunity [12, 13]. While others and we have shown that RANKL and OPG are expressed in atherosclerotic lesions in mice and humans, their roles in mediating vascular disease are not fully understood [5, $14,15]$. We previously observed that OPG deficiency in mice led to increased atherosclerosis, vascular calcification, and osteoporosis that were correlated with elevated circulating RANKL [16]. Further, treatment of LDLR-/mice with recombinant OPG reduced vascular calcification [17-19].

RANKL-Dependent Macrophage

Pro-Calcific Activity
Taken together, these data suggest that RANKL/ RANK may regulate vascular calcification and atherosclerosis. With the studies reported here, we show that RANKL regulates the interaction between macrophages and SMCs. Thus, we tested the hypothesis that RANKL regulates SMC calcification indirectly by modulating macrophage production of pro-calcific cytokines. We report that by using a bone marrow-derived macrophage (BMDM)/SMC co-culture system RANKL stimulates BMDM IL- 6 and TNF- $\alpha$ secretion that in turn enhances SMC calcification. Collectively, these data suggest that RANKL acts indirectly on SMC calcification by stimulating macrophages to produce pro-calcific mediators. Thus, inhibition of the RANKL/RANK pathway may be beneficial in reducing atherosclerotic lesion-associated mineralization.

\section{Materials and Methods}

Cells

Mouse SMCs and BMDMs were generated from C57BL6 mice. Animals were maintained in a specific pathogen-free environment at the University of Washington. Animals were sacrificed by $\mathrm{CO}_{2}$ euthanasia. The Institutional Animal Care and Use Committee, University of Washington, approved all protocols. The investigation conforms to the Guide for the Care and Use of Laboratory Animals published by the US National Institutes of Health (NIH Publication No. 85-23, revised 1996).

Mouse SMCs were generated from mouse aortas as described by Speer et al. [20]. Briefly, the media was carefully stripped from the thoracic and abdominal aorta under a dissection microscope and cut into $1-\mathrm{mm}$ pieces. The pieces were first treated with $1 \mathrm{mg} /$ $\mathrm{ml}$ collagenase for $20 \mathrm{~min}$ to remove residual endothelial and adventitial cells and then dispersed in a mixture of $1 \mathrm{mg} / \mathrm{ml}$ collagenase and $0.5 \mathrm{mg} / \mathrm{ml}$ elastase in culture medium containing FBS. After incubation at $37^{\circ} \mathrm{C}$ for $1 \mathrm{~h}$, medial cells were released. The cell suspension was centrifuged and re-suspended in DMEM containing $100 \mathrm{U} / \mathrm{ml}$ penicillin, $100 \mathrm{mg} / \mathrm{ml}$ streptomycin, and $20 \%$ FBS. Cells used for the experiments were primary cultures and subcultures of 3-9 passages. SMC phenotype and purity was determined by staining for SM- $\alpha$-actin, SM22 $\alpha$, and desmin (antiSM- $\alpha$-actin from Sigma, anti-SM $22 \alpha$ from Abcam, and anti-desmin from DAKO). BMDMs were isolated from mouse femurs and differentiated in the presence of macrophage colony stimulating factor (M-CSF) for 7 days. BMDM phenotype and purity were determined by FACS analysis for macrophage-specific antigen F4/80 (anti-F4/80 from Abcam). Neutralizing antibodies to mouse TNF- $\alpha$ and mouse IL- 6 were obtained from eBioscience (San Diego, Calif., USA).

\section{Cell Culture and BMDM/SMC Co-Culture}

SMCs were plated at $2 \times 10^{5}$ cells/well in 6 -well plates in DMEM supplemented with $10 \%$ FBS. The cells were cultured for 7 and 14 days in control medium (CM, DMEM with 3\% FBS containing $1.2 \mathrm{mM}$ inorganic phosphate) or in high phosphate me-

J Vasc Res 2012;49:510-521 

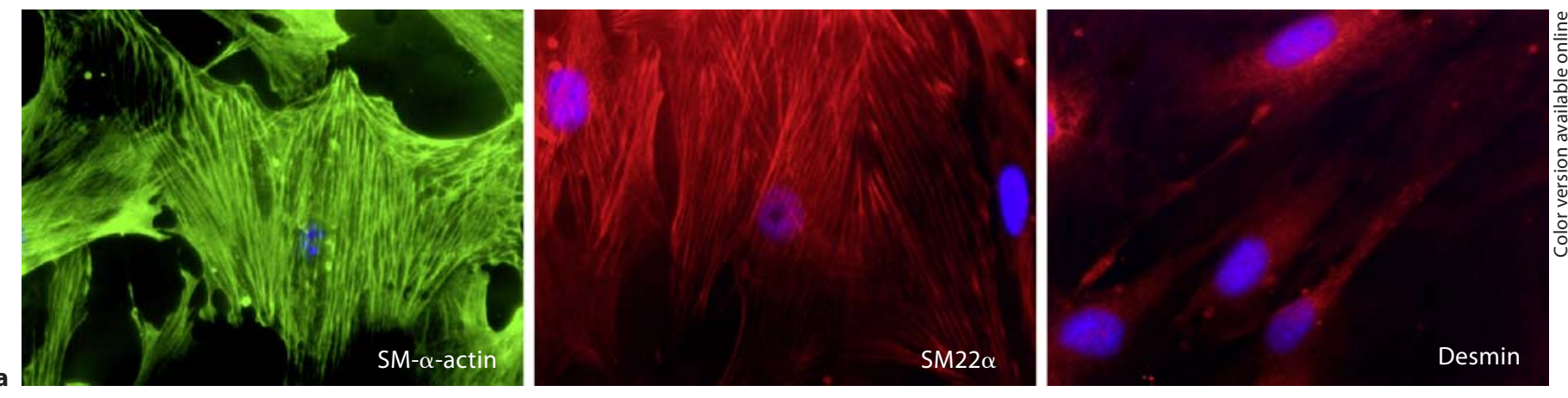

Fig. 1. SMC and BMDM characterization. Early passage SMCs were plated in chamber slides and stained by immunofluorescence for SM- $\alpha$-actin, SM $22 \alpha$, and desmin. a $100 \%$ of the cells express these SMC markers at high level. b BMDMs differentiated for 7 days with M-CSF were trypsinized and stained for the F4/80 macrophage-specific antibody. Nearly $97 \%$ of the cells are positive for this marker.

dium (HPM, DMEM with 3\% FBS plus $2.6 \mathrm{~mm}$ inorganic phosphate). BMDM/SMC co-culture was performed as described by $\mathrm{Li}$ et al. [21]. For BMDM/SMC co-culture experiments, SMCs were plated at $8 \times 10^{4}$ cells/well in 12-well plates and BMDMs were plated at $1.5 \times 10^{5}$ cells/transwell in separate 12 -well plates in RPMI containing $10 \%$ FBS and a source of M-CSF. The next day, the transwells were added to the SMC plates and treatments were started. Treatments continued every other day for 7 days. Transwell inserts with $0.22-\mu \mathrm{M}$ pore size were used (Corning Inc., Corning, N.Y., USA).

\section{PCR}

Total RNA was isolated from cells using the RNeasy kit (Qiagen, Chatsworth, Calif., USA). cDNA synthesis was performed using Omniscript reverse transcriptase from Qiagen. The PCR primers for mouse RANK were: forward 5'-AGATGTGGTCTGCAGCTCTTCCAT-3', and reverse 5'-ACACACTTCTTGCTGACTGGAGGT-3', amplifying a 278-bp fragment. Primers for RANKL were forward 5'-CGCTCTGTTCCTGTACTTTCGAGCG-3' andreverse 5'-TCGTGCTCCCTCCTTTCATCACAGGTT3', amplifying a 198-bp fragment.

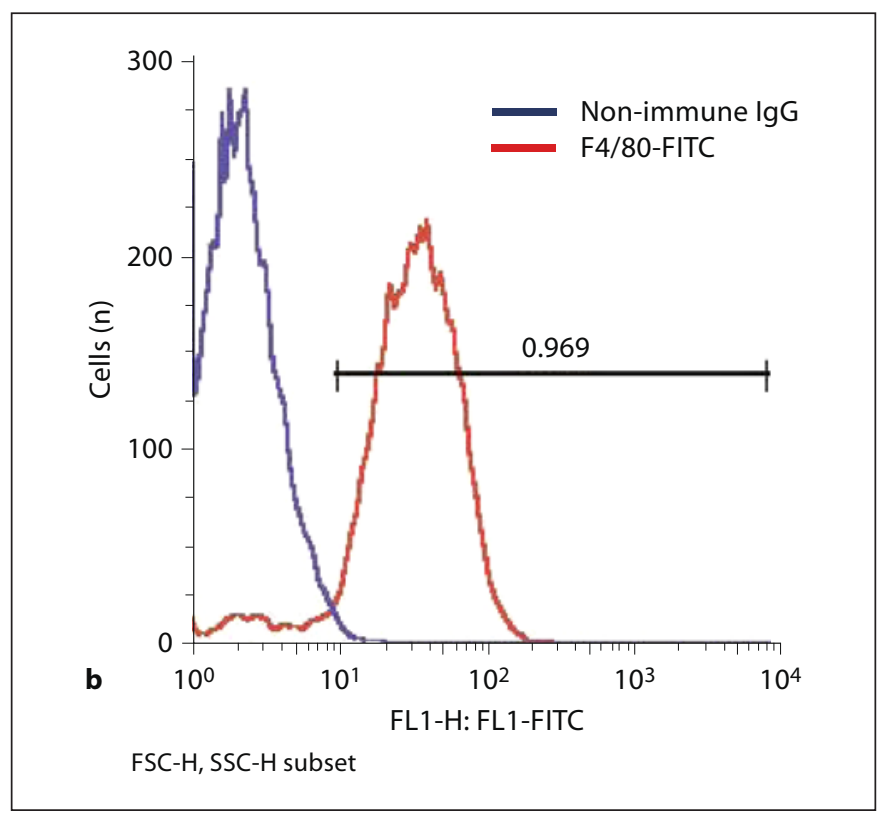

For quantitative PCR, we used TaqMan Gene Expression Assays (A\&BI Applied Biosystems): matrix Gla protein (MGP) Mm00441906.m1; alkaline phosphatase Mm00475834.m1; Pit1 Mm00489378.m1; Runx2 Mm00505584.m1, and 18S Mm02601777.g1. Quantification of gene expression was calculated by the standard curve method according to the manufacturer's protocol and normalized to $18 \mathrm{~S}$ rRNA.

\section{Calcium Assay}

Cell cultures were rinsed with PBS and decalcified with 0.6 $\mathrm{mM} \mathrm{HCl}$ at $4^{\circ} \mathrm{C}$ for $24 \mathrm{~h}$. Levels of calcium released from cell cultures were determined colorimetrically by the $o$-cresolphthalein complexone method as described previously (TECO calcium diagnostic kit) [22]. Calcium was normalized to cellular protein and expressed as microgram calcium per milligram protein.

\section{ELISA}

Conditioned media from BMDMs receiving various treatments were collected for measurement of secreted TNF- $\alpha$ and IL6 . ELISA kits from eBioscience were used. Reactions were performed according to the manufacturer's instructions. 


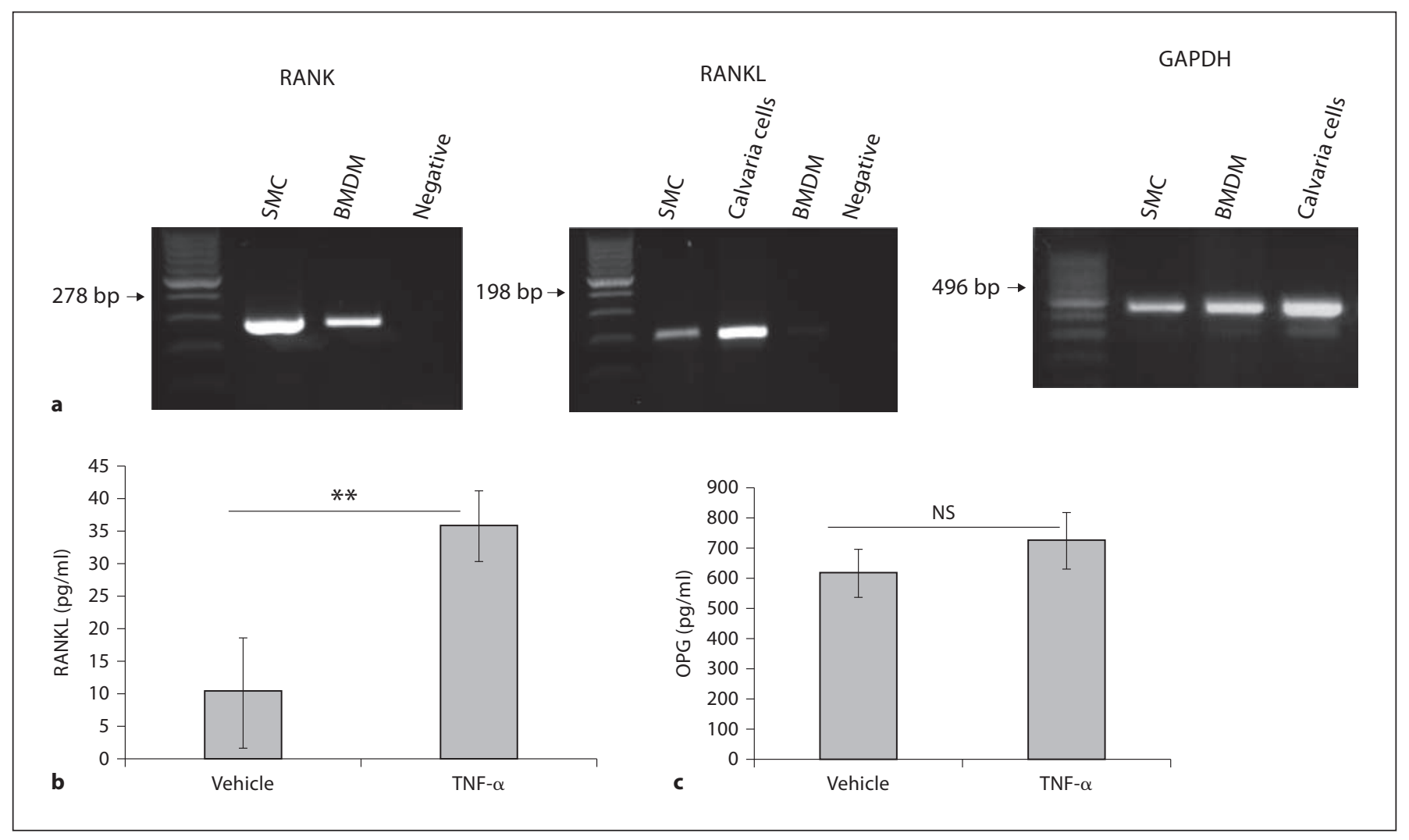

Fig. 2. RANK, RANKL, and OPG expression. a RT-PCR with RNA isolated from SMCs, BMDMs, and positive control calvaria cells. RANK was highly expressed in both SMCs and BMDMs. RANKL was also highly expressed in SMCs but not in BMDMs. Amplification of GAPDH was used to determine the quality of the RNA. b ELISA for RANKL and OPG in conditioned medium collected from SMCs. Cells were treated with vehicle or TNF- $\alpha$ for $48 \mathrm{~h}$. Very low RANKL protein was detected, ${ }^{* *} \mathrm{p}<0.05$. In contrast, very high levels of OPG were present.

Statistical Analysis

Data are shown as means \pm SD of at least 3 independent experiments. Significance between groups was analyzed with Student's t test or ANOVA followed by Fisher's protected least significant difference test. Data were considered statistically significant at a value of $\mathrm{p}<0.05$.

\section{Results}

SMC and BMDM Characterization and Expression of RANK, RANKL, and OPG in Mouse BMDMs and SMCs

We isolated SMCs from mouse aortas and characterized them for the expression of the SMC markers SM- $\alpha$ actin, SM22 $\alpha$, and desmin thus indicating the correct phenotype and nearly $100 \%$ purity (fig. 1a). BMDMs were isolated from mouse femur and differentiated for 7 days in M-CSF. These cells showed expression of the macrophage maker F4/80 but low expression of CD11c indicating that they are not dendritic cells (fig. $1 \mathrm{~b}$ and not shown). We next examined the expression of RANK and RANKL in mouse SMCs and BMDMs by reverse transcriptase (RT)-PCR. We found that both RANK and RANKL were expressed in SMCs (fig. 2a). BMDMs expressed high levels of RANK but almost undetectable RANKL. Protein analysis of RANKL expression in the conditioned medium by ELISA showed very low levels in SMCs that were increased by treatment with TNF- $\alpha$, a known RANKL inducer (fig. 2b). It is, however, important to point out that a high level of OPG interferes with the detection of RANKL by this method. Indeed, we observed high levels of OPG protein in the conditioned medium of SMCs. TNF- $\alpha$ does not seem to regulate OPG levels (fig. 2b). In 
Fig. 3. RANKL treatment does not enhance SMC calcification. Differentiated BMDMs do not form osteoclasts in response to RANKL. a SMCs were treated with CM or HPM in the presence of 100 ng/ml of RANKL or vehicle. b, c TRAP staining. b BMDM differentiated for 7 days in M-CSF $(20 \mathrm{ng} / \mathrm{ml})$ and then treated for 7 more days with M-CSF $(20 \mathrm{ng} / \mathrm{ml}$ ) and RANKL (50 ng/ml). c RAW 264.7 treated for 3 days with RANKL $(50 \mathrm{ng} / \mathrm{ml})$ form TRAP-positive multinucleated cells.
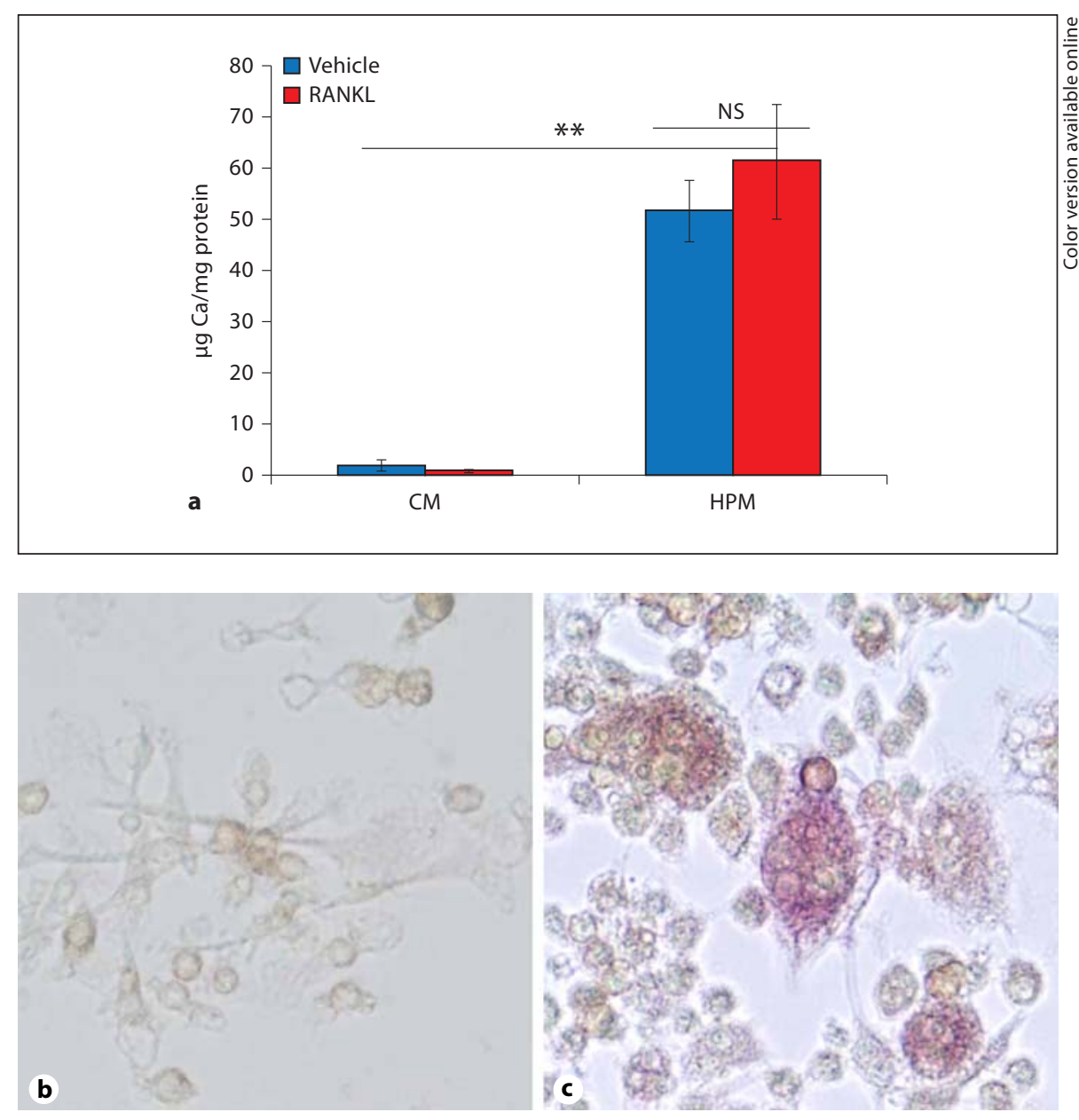

contrast, RANKL and OPG proteins could not be detected in BMDM cultures (not shown).

RANKL Does Not Have a Direct Effect on SMC

Calcification in vitro and Does Not Induce Osteoclast

Formation in M-CSF-Differentiated BMDMs

A previous study implicated RANKL as a pro-calcification agent for SMCs [23]. Therefore, we aimed to determine whether RANKL also induced SMC calcification in our system. We treated SMCs with CM, containing low phosphate medium, and HPM known to induce SMC calcification [24]. In addition, we treated both conditions with RANKL. As shown in figure 3a, SMCs treated for 10 days with HPM and RANKL did not calcify more than SMCs treated with HPM only. We also aimed to determine whether RANKL treatment of BMDMs differentiated with M-CSF could elicit osteoclast formation. Thus, we differentiated BMDMs from bone marrow cells for 7 days followed by treatment with RANKL for additional 7 days always in the presence of M-CSF. As shown in figure $3 \mathrm{~b}$, no TRAP-positive cells, indicative of an osteoclast phenotype, could be observed in the cultures. Figure 3c shows RAW264.7 cells treated with RANKL for 3 days forming multinucleated TRAP-positive cells (positive control).

\section{Enhancement of SMC Calcification in BMDM/SMC}

\section{Co-Cultures by RANKL}

Several groups have shown that macrophage/SMC coculture in HPM results in increased calcium deposition by SMCs, implying that macrophage-derived pro-calcific soluble factors act to enhance SMC mineralization [9-11, 21]. We hypothesized that addition of RANKL would further induce macrophage expression of pro-calcific factors and thus performed BMDM/SMC co-cultures in 12-well transwells with and without addition of RANKL. BMDM/ SMC co-cultures were cultured in either CM or HPM for 7 days. Calcium content in the extracellular matrix of the 
Fig. 4. RANKL enhances SMC calcification in BMDM/SMC cocultures. Transwell (0.22-mm pore size) co-cultures of SMCs and BMDMs grown in CM or high HPM were treated with RANKL $(100 \mathrm{ng} / \mathrm{ml})$ for 7 days or with vehicle. ${ }^{* *} \mathrm{p}<0.05$.

Fig. 5. RANKL induces expression of IL- 6 and TNF- $\alpha$ in BMDMs. BMDMs differentiated for 7 days with M-CSF were treated with CM or HPM and RANKL at $100 \mathrm{ng} / \mathrm{ml}$ or vehicle in absence of M-CSF for 6 days (a, b). BMDMs were treated with RANKL (100 ng/ml) and RANKL + OPG (200 ng/ml) for $48 \mathrm{~h}$ in serum-free RPMI (c, d). ELISAs for IL- 6 and TNF- $\alpha$ with BMDM supernatants. ${ }^{* *} \mathrm{p}<0.01$ for RANKL-treated vs. vehicle $(\mathbf{a}, \mathbf{b})$ and RANKL vs. vehicle and RANKL + OPG $(\mathbf{c}, \mathbf{d})$.

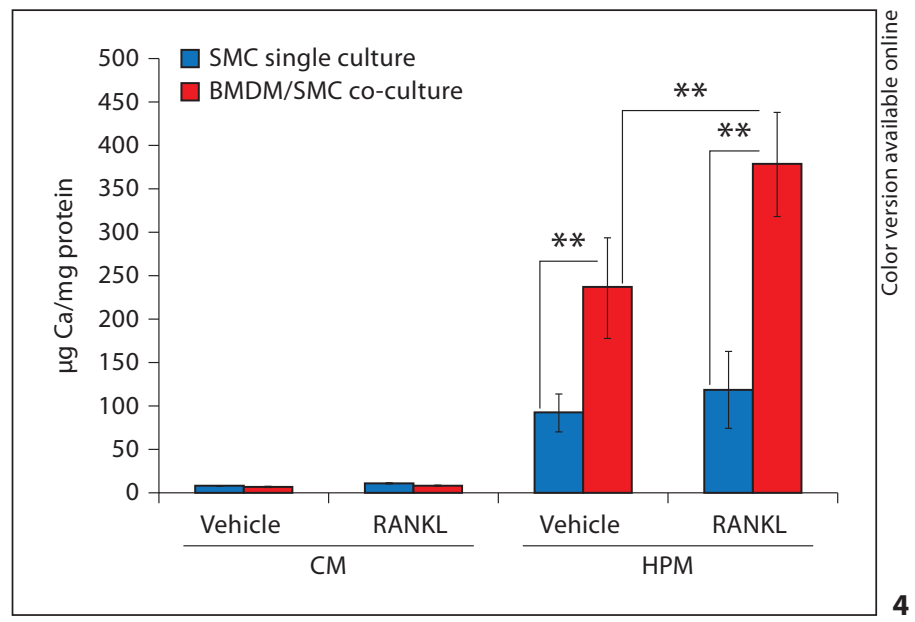

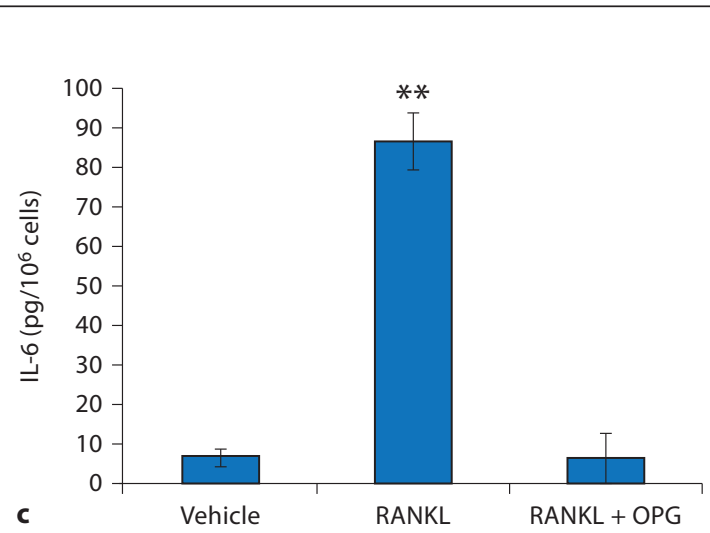

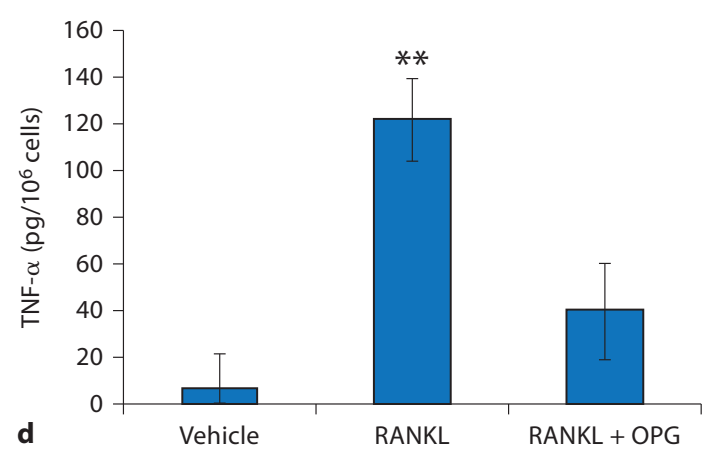

SMC layer was then determined. As shown in figure 4, treatment of BMDM/SMC co-cultures with RANKL in HPM increased SMC calcification when compared to vehicle-treated BMDM/SMC co-cultures. However, again RANKL did not enhance SMC mineralization in single SMC cultures. In keeping with the previous reports, SMC matrices in BMDM/SMC co-cultures had increased mineralization when compared to the single SMC cultures independent of RANKL treatment. There was no calcification when SMCs were cultured in CM regardless of the treatment or the type of culture. As hypothesized, the enhanced calcification observed in RANKL-treated 


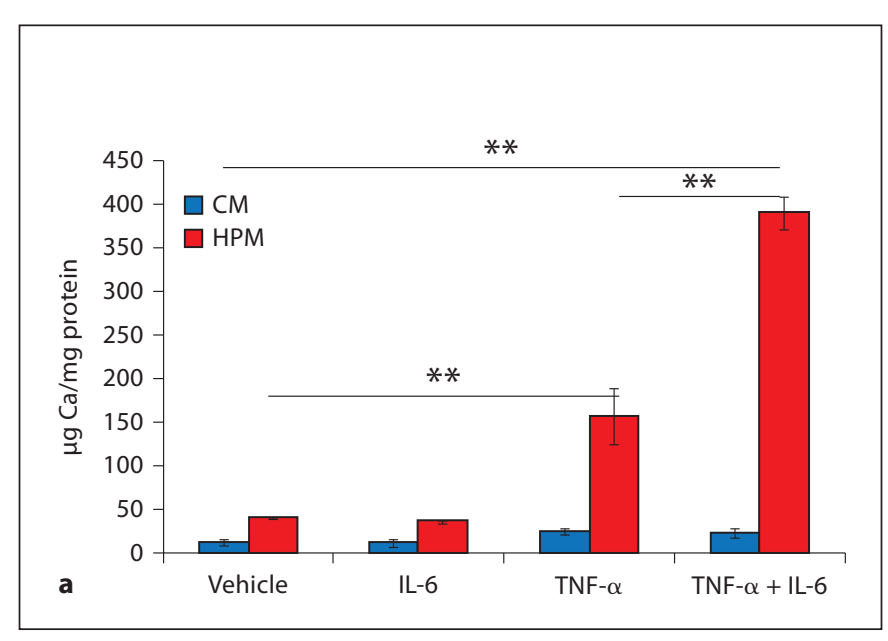

Fig. 6. TNF- $\alpha$ and TNF- $\alpha /$ IL- 6 combination enhance SMC mineralization. a SMCs were cultured in CM or HPM with the addition of IL- 6 at $50 \mathrm{ng} / \mathrm{ml}$, TNF- $\alpha$ at $10 \mathrm{ng} / \mathrm{ml}$, or a combination of the two factors. ${ }^{* *} \mathrm{p}<0.01$. $\mathbf{b}$ SMCs were cultured for 7 days in HPM and treated with increasing concentrations of TNF- $\alpha(0.5$, 2 , 5, and $10 \mathrm{ng} / \mathrm{ml}){ }^{* *} \mathrm{p}<0.05$. c SMCs were cultured for 7 days in HPM and treated with $2 \mathrm{ng} / \mathrm{ml}$ of TNF- $\alpha$ alone or in combination with increasing concentrations of IL- $6(5,10$, and $50 \mathrm{ng} / \mathrm{ml})$. ${ }^{* *} \mathrm{p}<0.05$.

BMDM/SMC co-cultures suggests that RANKL induces macrophages to release additional soluble factors that further augment SMC matrix calcification.

\section{Regulation of Macrophage Secretion of}

Pro-Inflammatory Cytokines by RANKL

To characterize which factors modulate the RANKLdependent enhancement of calcification in SMC/BMDM co-cultures, we next tested whether RANKL induced macrophage-derived secreted factors known to regulate SMC mineralization. We treated BMDMs differentiated for 7 days with M-CSF, with $100 \mathrm{ng} / \mathrm{ml}$ of RANKL for 3 and 6 days in CM and HPM and measured the levels of IL- 6 and TNF- $\alpha$. As shown in figure $5 a, b$, unchallenged BMDMs cultured in CM and HPM secreted very low levels of IL- 6 and TNF- $\alpha$. However, addition of RANKL induced strong secretion of IL- 6 and TNF- $\alpha$ in both media. Co-treatment with RANKL and its decoy receptor OPG
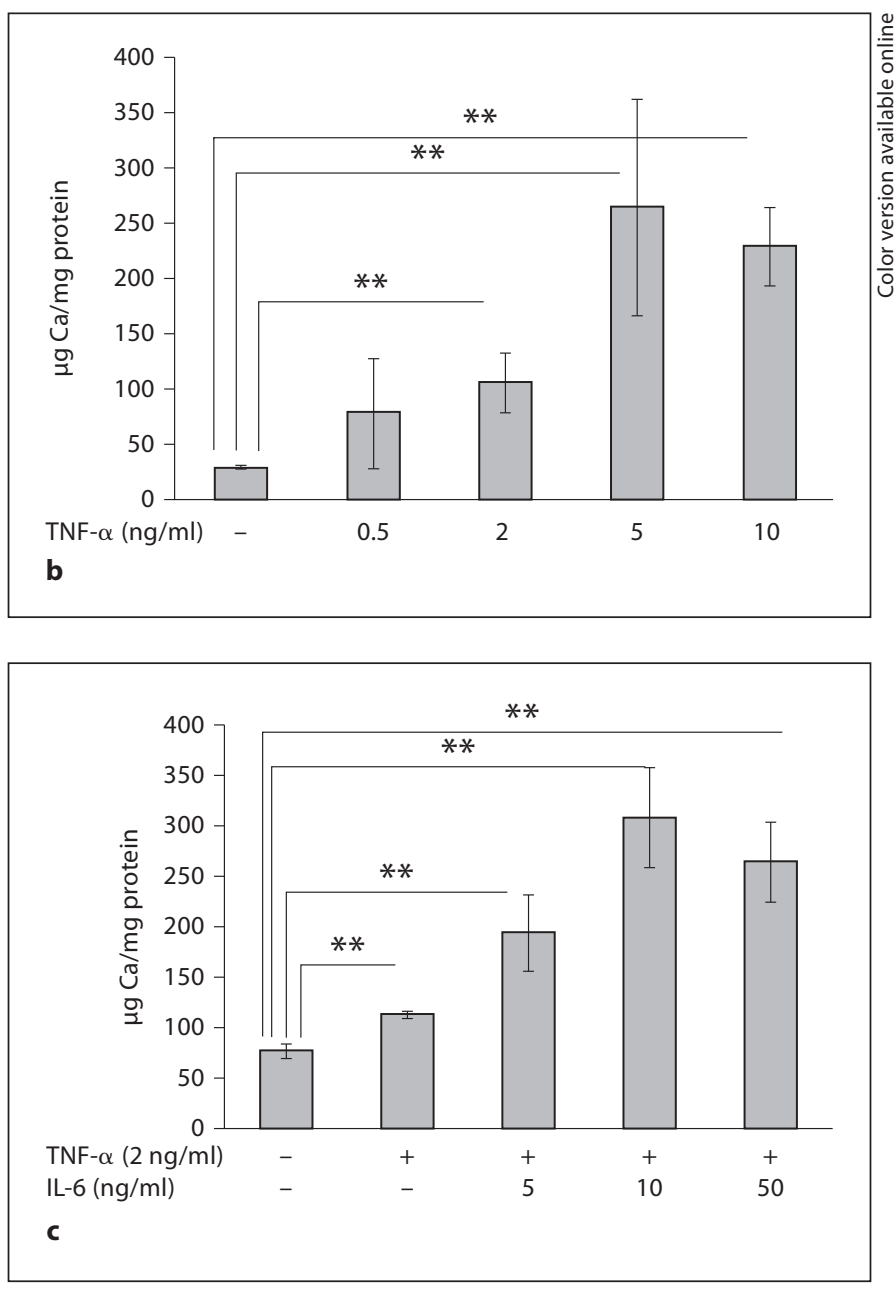

abrogated cytokine induction, indicating that the effects are indeed mediated by RANKL (fig. 5c, d). In addition, RANKL synergized with lipopolysaccaride to further enhance IL- 6 and TNF- $\alpha$ production (not shown). Both TNF- $\alpha$ and IL- 6 are known pro-inflammatory factors and inducers of mineralization $[10,25]$.

\section{Regulation of SMC Calcification by TNF- $\alpha$ and IL-6}

To determine whether TNF- $\alpha$ and IL- 6 could indeed induce SMC mineralization in our system, we performed calcification assays by incubating single SMC cultures with TNF- $\alpha$ and IL-6, alone or in combination in CM and HPM. We found that after 7 days of treatment TNF$\alpha($ at $10 \mathrm{ng} / \mathrm{ml})$, but not IL-6 (at $50 \mathrm{ng} / \mathrm{ml})$, enhanced SMC mineralization. However, the combination of the two factors further enhanced the mineralization induced by TNF- $\alpha$ treatment, suggesting a synergistic effect (fig. 6a). Further, we titrated the minimum concentration of TNF- 


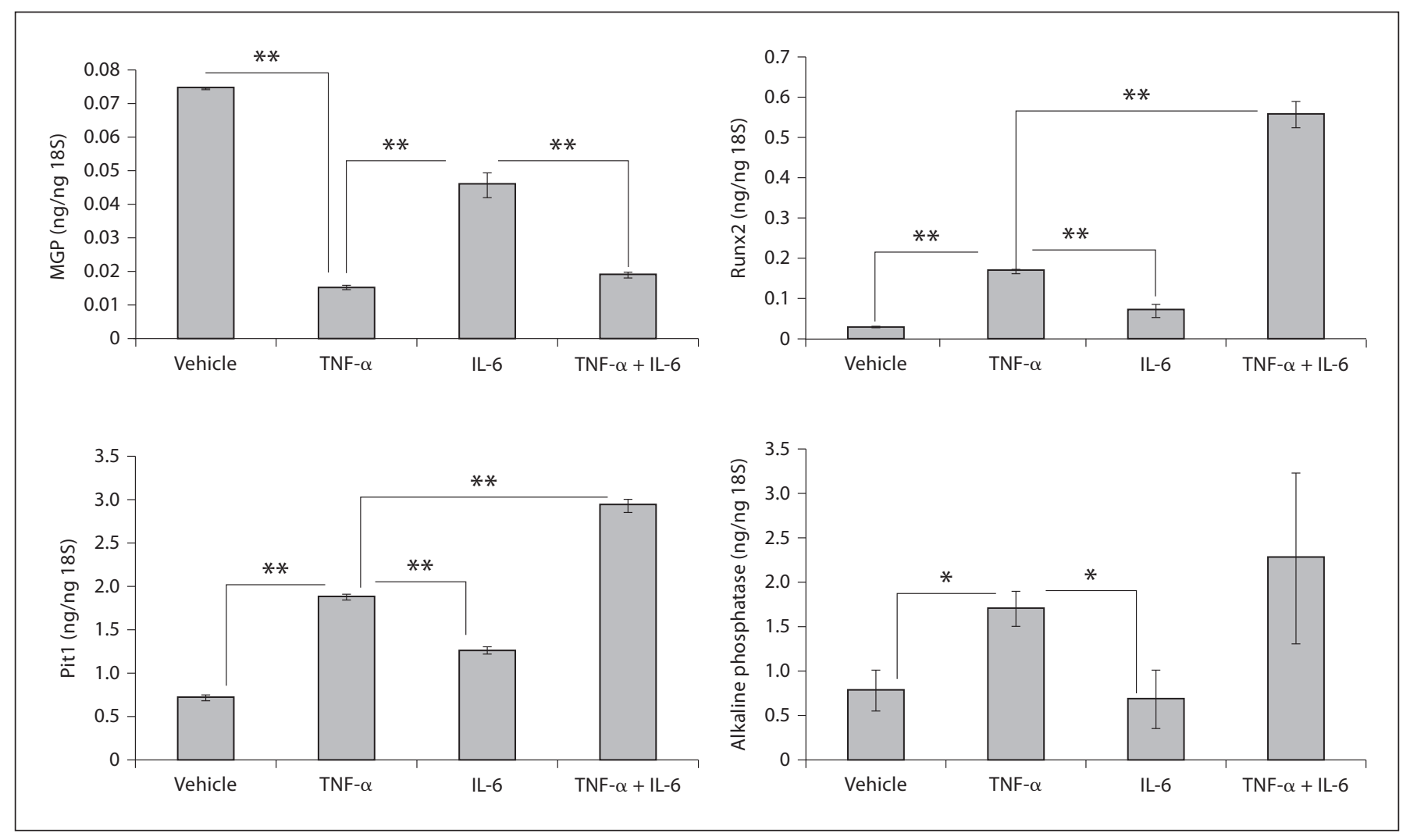

Fig. 7. TNF- $\alpha$ and IL-6 regulate calcification genes. SMCs were cultured in DMEM containing $3 \%$ FBS and treated with vehicle, TNF- $\alpha$ at $10 \mathrm{ng} / \mathrm{ml}$, IL- 6 at $50 \mathrm{ng} / \mathrm{ml}$, or a combination of TNF- $\alpha$ and IL- 6 for $48 \mathrm{~h}$. RNA was extracted and analyzed by quantitative PCR for MGP, Runx2, Pit1, and alkaline phosphatase. Data shown were normalized to $18 \mathrm{~S}$ ribosomal RNA of the samples and are presented as means \pm SD. ${ }^{* *} \mathrm{p}<0.01$ and ${ }^{*} \mathrm{p}<0.05$.

$\alpha$ and the minimum concentration of the combination of TNF- $\alpha$ and IL- 6 able to induce SMC calcification. As shown in figure $6 \mathrm{~b}, 2 \mathrm{ng} / \mathrm{ml}$ of TNF- $\alpha$ was sufficient to enhance SMC mineralization induced by HPM. The combination of $2 \mathrm{ng} / \mathrm{ml}$ of TNF- $\alpha$ with $5 \mathrm{ng} / \mathrm{ml}$ of IL- 6 was sufficient to further enhance SMC mineralization (fig. 6c). These concentrations are about 10- to 15 -fold higher than the amount of TNF- $\alpha$ and IL- 6 produced by macrophages in response to RANKL (on a per cell basis). However, it has to be pointed out that the macrophages continuously produce cytokines, whereas treatments are added every other day.

In the attempt to elucidate the mechanism(s) behind TNF- $\alpha$ and IL- 6 effects, we examined whether these cytokines regulate known calcification genes. We found that TNF- $\alpha$ is more potent than IL- 6 in inducing the procalcific genes Pit1, alkaline phosphatase and Runx2, and in inhibiting the anti-calcific gene MGP. Treatment withIL- 6 and TNF- $\alpha$ either had no additional effect above
TNF- $\alpha$ (alkaline phosphatase and MGP) or acted additively with TNF- $\alpha$ (Pit1 and Runx2) on gene expression (fig. 7).

Inhibition of IL- 6 and TNF- $\alpha$ in BMDM/SMC Co-Culture Prevents RANKL-Mediated Enhancement of SMC Calcification

To determine whether RANKL induction of IL- 6 and TNF- $\alpha$ was required for BMDM stimulation of SMC calcification, we performed studies with antibodies neutralizing IL- 6 and TNF- $\alpha$ activity. BMDM/SMC co-cultures grown in HPM were treated with vehicle or RANKL and simultaneously with neutralizing IL- 6 and TNF- $\alpha$ antibodies, alone or in combination. After 7 days of treatment, the calcium content of the extracellular matrix of the SMC layer was measured. As shown in figure 8 , inhibition of IL- 6 or TNF- $\alpha$ activity abrogated the ability of RANKL to enhance BMDM/SMC co-culture calcification. In addition, neutralizing both IL- 6 and TNF- $\alpha$ ap- 


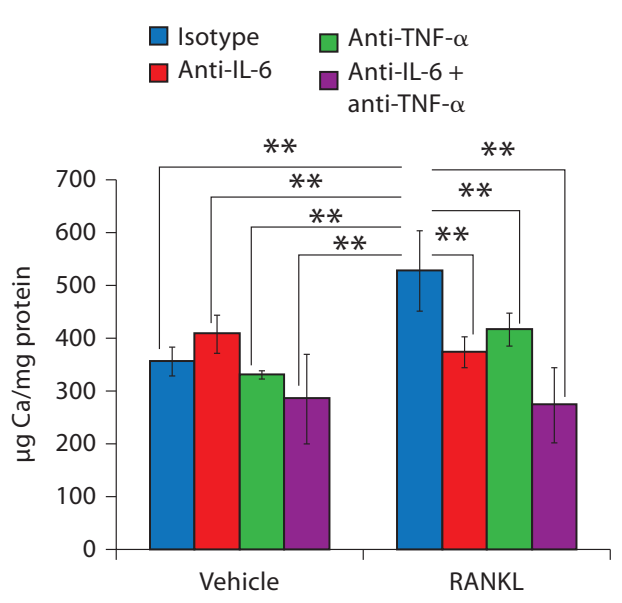

Fig. 8. Inhibition of TNF- $\alpha$ and IL- 6 reduces RANKL-dependent stimulation of SMC calcification. Transwell $(0.22-\mu \mathrm{m}$ pore size) co-cultures of SMCs and BMDMs in HPM were treated with RANKL at $100 \mathrm{ng} / \mathrm{ml}$ with and without neutralizing antibodies to TNF- $\alpha(1 \mu \mathrm{g} / \mathrm{ml})$ and IL- $6(1 \mu \mathrm{g} / \mathrm{ml})$. Calcium content in the SMC layer was measured after 7 days of culture. ${ }^{* *} \mathrm{p}<0.05$. In the RANKL-treated co-cultures, isotype control is statistically different from all the treatments. RANKL treatment isotype control is statistically different from all the groups in vehicle treatment.

peared to further decrease RANKL induction of SMC mineralization. In contrast, treatment with IL-6- and TNF- $\alpha$-neutralizing antibodies did not reduce calcification in vehicle-treated BMDM/SMC co-cultures. These results indicate that RANKL effects are mediated completely by IL- 6 and TNF- $\alpha$.

\section{Discussion}

Vascular calcification, a type of ectopic soft tissue mineralization, increases the risk of cardiovascular mortality [1]. Increasing clinical evidence suggests that RANKL may play an important role in CVD [26-28]. In the Bruneck Study of over 900 subjects, baseline serum RANKL was a highly significant predictor of CVD risk (including ischemic stroke, transient ischemic attack, myocardial infarction, and vascular death) [29]. The Tromsø study, a larger more recent study, also provides epidemiological support for a role of RANKL in vascular disease. The main finding was that baseline levels of soluble RANKL significantly predicted the risk for CVD over a 15-year follow-up period [30]. Further, correlation between RANKL levels and high circulating phosphate levels has been reported in chronic kidney disease patients, a population that is affected by extensive medial and intimal calcification and significant increase in cardiovascular mortality compared to the general population [31].

We have previously reported that OPG deficiency in ApoE-/- mice led to increased atherosclerosis, vascular calcification, and osteoporosis that also correlated with increased circulating RANKL. Others and we have also shown that RANKL is expressed in atherosclerotic lesions in mice and humans. These observations suggest that elevated RANK/RANKL signaling might be a unique driver of CVD [16]. However, the mechanism(s) by which RANK/RANKL plays a role in mediating vascular disease are still not fully understood. Furthermore, it is still not clear which cell types produce and which respond to RANKL in the atherosclerotic lesion. RANKL was found to be elevated in the matrix of human advanced calcified lesions in the aorta, while its inhibitor OPG was increased in normal aorta but decreased in the advanced lesions [14]. RANKL, RANK, and OPG were all found associated with thrombotic material in ruptured coronary plaques [15]. Further, increased RANKL expression has been reported in $\mathrm{T}$ cells and increased RANK expression in monocytes in the lesions of patients with unstable angina [15]. In ApoE-/- mouse lesions, we found RANKL expressed in plaque chondrocyte-like cells [5]. In vitro, SMCs have been reported to express RANKL in response to oxidative stress. In addition, endothelial cells express RANKL in response to inflammatory cytokines, as do activated T cells [32-35]. Other in vitro studies and this report have shown that RANK is expressed on endothelial cells, SMCs, and monocytes-macrophages [36, 37]. Together these data indicate that the RANKL/RANK/ OPG system is likely to affect the local environment of the lesion.

Atherosclerosis is considered to be a chronic inflammatory disease. Immune/inflammatory cells belonging to both arms of the immune system are always present in the atherosclerotic lesion. Macrophages are the most abundant, however T cells (especially CD4+) and antigen-presenting dendritic dells are found in atherosclerotic lesions as well [38-40]. Macrophages infiltrating the vessel wall are often localized in the vicinity of SMCs and mineralized areas. Plaque macrophages produce pro-inflammatory cytokines known to induce SMC apoptosis and osteogenic differentiation. In co-culture systems these effects have been shown to be mediated at least in 
part by TNF- $\alpha$ [8-11]. Using BMDMs as a source of macrophages in a co-culture system, we confirmed that mouse macrophages enhanced mouse SMC mineralization in a paracrine fashion. Most importantly, using the same assay, we found that RANKL treatment of BMDM/ SMC co-cultures greatly increased the extent of mineralization when compared to co-cultures treated with vehicle. The observed RANKL effect on SMC calcification was mediated by the macrophages since RANKL did not affect SMC mineralization in single culture despite the high level of RANK expression by both the SMCs and BMDMs. RANKL has been reported by Panizo et al. [23] to induce mineralization in rat SMCs in a BMP-4-dependent manner. However, in agreement with our data, a recent report by Byon et al. [34] using mouse SMCs showed no effect of RANKL on SMC mineralization. The difference in SMC species origin (rat versus mouse) may account for the discrepancy in the data. In our system, the lack of RANKL effect on SMC mineralization may also be due to the high expression of OPG by the mouse SMCs.

We hypothesized that in BMDMs RANKL may regulate the expression of cytokines or other factors known to modulate SMC mineralization. In support of this hypothesis, we found that mouse BMDMs expressed very low levels of TNF- $\alpha$ and IL- 6 in resting state while these pro-atherogenic and pro-calcifying factors were greatly up-regulated by RANKL treatment. This confirms similar studies performed with human-derived macrophages [41].

The RANKL-mediated enhancement of SMC calcification in the co-culture with BMDMs was dependent on TNF- $\alpha$ and IL- 6 . TNF- $\alpha$ was the first macrophage product to be shown to enhance SMC calcification in vitro and in vivo $[3,10,11]$. Elegant in vivo studies by Al-Aly et al. [42] have shown that TNF- $\alpha$ induces vascular calcification by mediating the oxidative stress-dependent regulation of osteogenic transcription regulators and pro-mineralization growth factors. In vitro, macrophage-derived TNF- $\alpha$ has also been shown to mediate SMC calcification. Finally, genetic studies in mice indicate that TNF- $\alpha$ signaling is also pro-atherosclerotic $[43,44]$. There have been less extensive investigations of the mechanisms behind IL-6 regulation of calcification. In recent studies, Yao et al. [25] showed that IL-6 inhibits MGP function via HSP70. Net inhibition of MGP results in higher activity of BMP-2. Clinically, TNF- $\alpha$ and IL- 6 have been shown to be independent predictors of cardiovascular events in chronic kidney disease patients [45]. Importantly, the RANKL/OPG system also appears to be highly dysregulated in patients affected by renal failure [31].
RANKL was first identified as the master regulator of osteoclastogenesis. Osteoclasts are large multinucleated cells able to resorb bone. Deletion of RANKL or RANK in mice results in severe osteopetrosis because of markedly reduced numbers of osteoclasts [46]. Osteoclast precursors, macrophages, and dendritic cells share the same myeloid precursor. Indeed, functional osteoclasts can be derived in vitro from bone marrow cells following simultaneous incubation with RANKL and M-CSF [47]. In our studies, macrophages were first differentiated from bone marrow cells with M-CSF and then treated with RANKL. With this protocol, we did not observe any formation of multinucleated cells or TRAP-positive cells, suggesting that differentiated macrophages cannot be induced to form multinucleated cells. It is still unclear whether RANKL drives osteoclast formation in atherosclerotic lesions. Osteoclast-like cells are found, albeit rarely, in human atherosclerotic lesions, and more recently TRAPpositive cells have been shown in mouse lesions $[1,34]$. It is thus possible that plaque cell-derived RANKL is able to induce osteoclast formation outside of the bone, even if in small numbers. Nevertheless, these putative osteoclast-like cells in the lesions do not seem sufficient to inhibit the progression of vascular calcification. We thus favor the hypothesis that RANKL in lesions may be activating pro-calcification pathways in plaques by activating macrophages. We propose that RANKL produced in the plaque by activated T cells, SMCs, and endothelial cells (likely in response to inflammatory cytokines and oxidation products) acts on macrophages and induces production of pro-calcific molecules.

In conclusion, these studies support the above hypothesis by showing for the first time that RANKL enhances macrophage pro-calcific function by up-regulation of the expression and secretion of pro-mineralization factors. These data mechanistically support our previous findings that lack of physiological RANKL inhibition in vivo leads to accelerated vascular calcification and increased lesion size in ApoE-/- mice [16] and suggests that inhibition of the RANKL/RANK pathway may be a viable therapeutic approach to ameliorate vascular calcification and CVD.

\section{Acknowledgment} M.S.

This work was supported by NIH-NHLBI grant HL093469 to

J Vasc Res 2012;49:510-521 519 


\section{References}

$>1$ Sage AP, Tintut Y, Demer LL: Regulatory mechanisms in vascular calcification. Nat Rev Cardiol 2010;7:528-536.

-2 Moe SM, Reslerova M, Ketteler M, O’Neill K, Duan D, Koczman J, Westenfeld R, JahnenDechent W, Chen NX: Role of calcification inhibitors in the pathogenesis of vascular calcification in chronic kidney disease (CKD). Kidney Int 2005;67:2295-2304.

$>3$ Shao JS, Cheng SL, Sadhu J, Towler DA: Inflammation and the osteogenic regulation of vascular calcification: a review and perspective. Hypertension 2010;55:579-592.

4 Abedin M, Tintut Y, Demer LL: Vascular calcification: mechanisms and clinical ramifications. Arterioscler Thromb Vasc Biol 2004;24:1161-1170.

$\checkmark 5$ Rattazzi M, Bennett BJ, Bea F, Kirk EA, Ricks JL, Speer M, Schwartz SM, Giachelli CM, Rosenfeld ME: Calcification of advanced atherosclerotic lesions in the innominate arteries of ApoE-deficient mice: potential role of chondrocyte-like cells. Arterioscler Thromb Vasc Biol 2005;25:1420-1425.

$\checkmark 6$ Lau WL, Pai A, Moe SM, Giachelli CM: Direct effects of phosphate on vascular cell function. Adv Chronic Kidney Dis 2011;18: 105-112.

$>7$ Lau WL, Festing MH, Giachelli CM: Phosphate and vascular calcification: emerging role of the sodium-dependent phosphate cotransporter PiT-1. Thromb Haemost 2010; 104:464-470.

$>8$ Boyle JJ, Bowyer DE, Weissberg PL, Bennett MR: Human blood-derived macrophages induce apoptosis in human plaque-derived vascular smooth muscle cells by Fas-ligand/ Fas interactions. Arterioscler Thromb Vasc Biol 2001;21:1402-1407.

$>9$ Tintut Y, Patel J, Territo M, Saini T, Parhami F, Demer LL: Monocyte/macrophage regulation of vascular calcification in vitro. Circulation 2002;105:650-655.

10 Tintut Y, Patel J, Parhami F, Demer LL: Tumor necrosis factor-alpha promotes in vitro calcification of vascular cells via the cAMP pathway. Circulation 2000;102:2636-2642.

-11 Shioi A, Katagi M, Okuno Y, Mori K, Jono S, Koyama H, Nishizawa Y: Induction of bonetype alkaline phosphatase in human vascular smooth muscle cells: roles of tumor necrosis factor-alpha and oncostatin $\mathrm{M}$ derived from macrophages. Circ Res 2002;91:9-16.

-12 Yun TJ, Chaudhary PM, Shu GL, Frazer JK, Ewings MK, Schwartz SM, Pascual V, Hood LE, Clark EA: OPG/FDCR-1, a TNF receptor family member, is expressed in lymphoid cells and is up-regulated by ligating CD40. J Immunol 1998;161:6113-6121.

$\checkmark 13$ Yun TJ, Tallquist MD, Aicher A, Rafferty KL, Marshall AJ, Moon JJ, Ewings ME, Mohaupt M, Herring SW, Clark EA: Osteoprotegerin, a crucial regulator of bone metabolism, also regulates $\mathrm{B}$ cell development and function. J Immunol 2001;166:1482-1491.
14 Dhore CR, Cleutjens JP, Lutgens E, Cleutjens KB, Geusens PP, Kitslaar PJ, Tordoir JH, Spronk HM, Vermeer C, Daemen MJ: Differential expression of bone matrix regulatory proteins in human atherosclerotic plaques. Arterioscler Thromb Vasc Biol 2001;21:1998-2003.

15 Sandberg WJ, Yndestad A, Øie E, Smith C, Ueland T, Ovchinnikova O, Robertson AK, Müller F, Semb AG, Scholz H, Andreassen AK, Gullestad L, Damås JK, Frøland SS, Hansson GK, Halvorsen B, Aukrust P: Enhanced T-cell expression of RANK ligand in acute coronary syndrome: possible role in plaque destabilization. Arterioscler Thromb Vasc Biol 2006;26:857-863.

16 Bennett BJ, Scatena M, Kirk EA, Rattazzi M, Varon RM, Averill M, Schwartz SM, Giachelli CM, Rosenfeld ME: Osteoprotegerin inactivation accelerates advanced atherosclerotic lesion progression and calcification in older ApoE-/- mice. Arterioscler Thromb Vasc Biol 2006;26:2117-2124.

17 Morony S, Tintut Y, Zhang Z, Cattley RC, Van G, Dwyer D, Stolina M, Kostenuik PJ, Demer LL: Osteoprotegerin inhibits vascular calcification without affecting atherosclerosis in $\operatorname{ldl}(-/-)$ mice. Circulation 2008; 117:411-420.

18 Anderson DM, Maraskovsky E, Billingsley WL, Dougall WC, Tometsko ME, Roux ER, Teepe MC, DuBose RF, Cosman D, Galibert L: A homologue of the TNF receptor and its ligand enhance T-cell growth and dendriticcell function. Nature 1997;390:175-179.

19 Wong BR, Rho J, Arron J, Robinson E, Orlinick J, Chao M, Kalachikov S, Cayani E, Bartlett FS, Frankel WN, Lee SY, Choi Y: TRANCE is a novel ligand of the tumor necrosis factor receptor family that activates cJun N-terminal kinase in T cells. J Biol Chem 1997;272:25190-25194.

-20 Speer MY, Chien YC, Quan M, Yang HY, Vali $\mathrm{H}$, McKee MD, Giachelli CM: Smooth muscle cells deficient in osteopontin have enhanced susceptibility to calcification in vitro. Cardiovasc Res 2005;66:324-333.

21 Li X, Speer MY, Yang H, Bergen J, Giachelli CM: Vitamin D receptor activators induce an anticalcific paracrine program in macrophages: requirement of osteopontin. Arterioscler Thromb Vasc Biol 2010;30:321-326.

-22 Sangiorgi G, Rumberger JA, Severson A, Edwards WD, Gregoire J, Fitzpatrick LA, Schwartz RS: Arterial calcification and not lumen stenosis is highly correlated with atherosclerotic plaque burden in humans: a histologic study of 723 coronary artery segments using nondecalcifying methodology. J Am Coll Cardiol 1998;31:126-133.
23 Panizo S, Cardus A, Encinas M, Parisi E, Valcheva P, López-Ongil S, Coll B, Fernandez E, Valdivielso JM: RANKL increases vascular smooth muscle cell calcification through a RANK-BMP4-dependent pathway. Circ Res 2009; 104:1041-1048.

-24 Wada T, McKee MD, Steitz S, Giachelli CM: Calcification of vascular smooth muscle cell cultures: inhibition by osteopontin. Circ Res 1999;84:166-178.

25 Yao Y, Watson AD, Ji S, Boström KI: Heat shock protein 70 enhances vascular bone morphogenetic protein- 4 signaling by binding matrix Gla protein. Circ Res 2009;105: 575-584.

26 Jono S, Otsuki S, Higashikuni Y, Shioi A, Mori K, Hara K, Hashimoto H, Ikari Y: Serum osteoprotegerin levels and long-term prognosis in subjects with stable coronary artery disease. J Thromb Haemost 2010;8: 1170-1175.

27 Schoppet M, Sattler AM, Schaefer JR, Herzum M, Maisch B, Hofbauer LC: Increased osteoprotegerin serum levels in men with coronary artery disease. J Clin Endocrinol Metab 2003;88:1024-1028.

28 Ueland T, Yndestad A, Øie E, Florholmen G, Halvorsen B, Frøland SS, Simonsen S, Christensen G, Gullestad L, Aukrust P: Dysregulated osteoprotegerin/RANK ligand/RANK axis in clinical and experimental heart failure. Circulation 2005; 111:2461-2468.

$\checkmark 29$ Kiechl S, Schett G, Schwaiger J, Seppi K, Eder P, Egger G, Santer P, Mayr A, Xu Q, Willeit J: Soluble receptor activator of nuclear factorkappa B ligand and risk for cardiovascular disease. Circulation 2007;116:385-391.

30 Jørgensen L, Hansen JB, Brox J, Mathiesen E, Vik A, Jacobsen BK: Serum osteoprotegerin levels are related to height loss: the Tromsø Study. Eur J Epidemiol 2011;26:305-312.

-31 Fahrleitner-Pammer A, Dobnig H, Dimai HP, Holzer H, Benesch T, Borchhardt K, Cejka D, Haas M: The effect of RANKL and OPG on bone mineral density in pre-dialysis chronic renal failure. Clin Nephrol 2009;71: 652-659.

-32 Collin-Osdoby P, Rothe L, Anderson F, Nelson M, Maloney W, Osdoby P: Receptor activator of NF-kappa B and osteoprotegerin expression by human microvascular endothelial cells, regulation by inflammatory cytokines, and role in human osteoclastogenesis. J Biol Chem 2001;276:20659-20672.

33 Kong YY, Feige U, Sarosi I, Bolon B, Tafuri A, Morony S, Capparelli C, Li J, Elliott R, McCabe S, Wong T, Campagnuolo G, Moran E, Bogoch ER, Van G, Nguyen LT, Ohashi PS, Lacey DL, Fish E, Boyle WJ, Penninger JM: Activated $\mathrm{T}$ cells regulate bone loss and joint destruction in adjuvant arthritis through osteoprotegerin ligand. Nature 1999;402:304309 . 
-34 Byon CH, Sun Y, Chen J, Yuan K, Mao X, Heath JM, Anderson PG, Tintut Y, Demer LL, Wang D, Chen Y: Runx2-upregulated receptor activator of nuclear factor $\kappa \mathrm{B}$ ligand in calcifying smooth muscle cells promotes migration and osteoclastic differentiation of macrophages. Arterioscler Thromb Vasc Biol 2011;31:1387-1396.

- 35 Tseng W, Graham LS, Geng Y, Reddy A, Lu J, Effros RB, Demer L, Tintut Y: PKA-induced receptor activator of NF-kappaB ligand (RANKL) expression in vascular cells mediates osteoclastogenesis but not matrix calcification. J Biol Chem 2010;285:2992529931.

-36 McGonigle JS, Giachelli CM, Scatena M: Osteoprotegerin and RANKL differentially regulate angiogenesis and endothelial cell function. Angiogenesis 2009;12:35-46.

- 37 Min JK, Han KY, Kim EC, Kim YM, Lee SW, Kim OH, Kim KW, Gho YS, Kwon YG: Capsaicin inhibits in vitro and in vivo angiogenesis. Cancer Res 2004;64:644-651.
Bobryshev YV, Taksir T, Lord RS, Freeman MW: Evidence that dendritic cells infiltrate atherosclerotic lesions in apolipoprotein $\mathrm{E}$ deficient mice. Histol Histopathol 2001;16: 801-808.

39 Llodrá J, Angeli V, Liu J, Trogan E, Fisher EA, Randolph GJ: Emigration of monocyte-derived cells from atherosclerotic lesions characterizes regressive, but not progressive, plaques. Proc Natl Acad Sci USA 2004;101: 11779-11784.

40 Yilmaz A, Lochno M, Traeg F, Cicha I, Reiss C, Stumpf C, Raaz D, Anger T, Amann K, Probst T, Ludwig J, Daniel WG, Garlichs CD: Emergence of dendritic cells in ruptureprone regions of vulnerable carotid plaques. Atherosclerosis 2004;176:101-110.

41 Seshasayee D, Wang H, Lee WP, Gribling P, Ross J, Van Bruggen N, Carano R, Grewal IS: A novel in vivo role for osteoprotegerin ligand in activation of monocyte effector function and inflammatory response. J Biol Chem 2004;279:30202-30209.

-42 Al-Aly Z, Shao JS, Lai CF, Huang E, Cai J, Behrmann A, Cheng SL, Towler DA: Aortic Msx2-Wnt calcification cascade is regulated by TNF-alpha-dependent signals in diabetic Ldlr-/- mice. Arterioscler Thromb Vasc Biol 2007;27:2589-2596.
43 Xanthoulea S, Thelen M, Pöttgens C, Gijbels MJ, Lutgens E, de Winther MP: Absence of p55 TNF receptor reduces atherosclerosis, but has no major effect on angiotensin II induced aneurysms in LDL receptor deficient mice. PLoS One 2009;4:e6113.

44 Xiao N, Yin M, Zhang L, Qu X, Du H, Sun X, Mao L, Ren G, Zhang C, Geng Y, An L, Pan $\mathrm{J}$ : Tumor necrosis factor-alpha deficiency retards early fatty-streak lesion by influencing the expression of inflammatory factors in apoE-null mice. Mol Genet Metab 2009;96: 239-244.

45 Okamura DM, Himmelfarb J: Tipping the redox balance of oxidative stress in fibrogenic pathways in chronic kidney disease. Pediatr Nephrol 2009;24:2309-2319.

46 Leibbrandt A, Penninger JM: RANK/ RANKL: regulators of immune responses and bone physiology. Ann NY Acad Sci 2008; 1143:123-150.

47 Rajachar RM, Truong AQ, Giachelli CM: The influence of surface mineral and osteopontin on the formation and function of murine bone marrow-derived osteoclasts. J Mater Sci Mater Med 2008;19:3279-3285. 